\title{
Crop Field Classification using Data Fusion of Unmanned Aerial Vehicle (UAV) and Sentinel 2A satellite: the case of Oda Dhawata Kebele Cluster farmland, Oromia Region, Ethiopia
}

Melkamu Demelash ( $\square$ demelashmelkamu2005@gmail.com )

Binyam Tesfaw

Degefie Tibebe

\section{Research Article}

Keywords: UAV, Sentinel 2A, fusion, Random forest, maximum likelihood and crop type classification

Posted Date: December 14th, 2021

DOI: https://doi.org/10.21203/rs.3.rs-1166571/v1

License: (c) (i) This work is licensed under a Creative Commons Attribution 4.0 International License. Read Full License 


\section{Abstract}

Accurate crop classification using remote sensing based satellite imageries approach remains challenging due to mix in spectral signatures. Employing Unmanned Aerial Vehicle (UAV) together with satellite imageries is believed in improving crop classification at field. Accordingly, this study aims to evaluate the potential of UAV images by blending with Sentinel 2A satellite images for crop field classification in Ethiopian agricultural context. The main purpose of the blending is to upgrade and or improve the lower resolution of the data source that is the sentinel $2 \mathrm{~A}$ data which was $10 \mathrm{~m}$ resolution. In the study, UAV data was used and preprocessed. The preprocessing includes camera calibration, photo alignment, dense point cloud generation based on the estimated camera positioning of scouting crop types. Then, orthomosaic UAV image was generated from single dense point cloud. Then, the processed UAV data was fused with Sentinel 2A (medium resolution) satellite data using Gram Schmidt pan sharpening method.this method is the most approach that it can run large data sets of spatial resultions. For crop classification, the Random forest (RF) machine-learning algorithm and Maximum likelihood methods were applied. Apart from the UAV and S2A data, field data was collected for training the crop classification. The point field data was collected from Teff, Wheat, Faba bean, Barley and Sorghum crop fields The results show that RF classifier algorithm classifies the crop types with $94 \%$ overall accuracy whereas the Maximum likelihood classifier with $90 \%$ overall accuracy. This implies that fused image has a potential to be used for crop type classification together with relatively better classification technique with high accuracy level

\section{Introduction}

Remote sensing technology has a major role in data extraction of crop information and crop distribution mapping (Zhang Jiankang et al, 2012a). However, accurate crops classification remains difficult because of similar crop with different spectral signatures and different crops with same spectrum development within the field of agriculture. There are different approaches are employed to address the issue including use of UAV and blending of UAV with different satellite imageries. UAV-based remote sensing approach gains popularity not just for its high spatial and temporal resolution but also for its ability to get spectral with spatial data at the same time (Licheng Zhao, 2019).

Unmanned Aerial System, sometimes referred drone, Unmanned Aerial vehicle (UAV), Remotely piloted aerial systems (RPAS) are rapidly developing technologies that are used to collect data, such as digital imagery, pictures and videos using mounted cameras. The emergence and development of UAV remote sensing technology has provided new ideas for gathering of crop information (Freeman et al, 2015a; Mesas-Carrascosa et al, 2014a; Rokhmana et al, 2015a). UAV remote sensing plays a good role and might generate additional feasible crop distribution information that could be significant to the development and application of crop monitoring technology.

Nowadays, UAV are changing the game in application of remote sensing (RS) in the agricultural sector by making data capture more affordable and timely accessible for crop classification and crop monitoring. 
UAV role in agriculture are becoming important systems to collect data for precision agriculture and improve sustainability, efficiency and productivity of the agricultural practices. UAV help precision agriculture through helping variable rate mapping, and guide targeted farm management activities. The high and flexible spatiotemporal resolution makes UAV potentially affordable and important system for agricultural application. Most agricultural activities are influenced by spatial and temporal variability. Hence, agriculture needs large volume of spatiotemporal data to capture the highly varying spatial and temporal agricultural production factors. As the future trend is to move to precision agriculture, cost, labor and time efficient technologies for the agriculturally data collection and analysis systems need to be in place. Apart from using only UAV images for crop classification, blending with satellite imageries are giving good performance for different agricultural application including crop classification. Some work has been done regarding the fusion of UAV and satellite data. Yilmaz (2016) compared the methods of criteria-based fusion algorithm, Gram-Schmidt, FuzeGo, High-Pass Filtering, Ehlers, Hyper spherical Color Space, Modified IHS and Adaptive Wavelet-Based algorithms in fusing aWorldView-2 MS (1.85 m) and a UAV image $(0.10 \mathrm{~m})$. The results showed that the criteria-based algorithm was very successful in keeping the color content and gave satisfactory spatial detail enhancement compared to other algorithms. However, the high price of Worldview-2 data limits its applications. Landsat and UAV data fusion have also been found to help crop identification results (Jenerowicz et al 2016). In this study, the authors compared the methods of Gram-Schmidt and PCA method in fusing Landsat 8 OLI MS (30 m) and UAV $(0.04 \mathrm{~m})$. The results showed that the methods used in this study were fast and easy to implement and generated fused images with high integration quality colour (the Gram- Schmidt method) and spatial detail. The visual assessment revealed that the worst results were obtained from the PCA method, but the spatial resolution of Landsat is relatively low in the case of smaller-scale agriculture. The recently launched Sentinel-2A provides an important data source for crop classification due to its free availability, stable data quality and high spatial resolution. Yet, few studies exist on fusing Sentinel-2A data with UAV for finer crop classification. The spatial resolution of a UAV depends on the flight height and the sensors. In practice, higher spatial resolutions require a longer data acquisition time and generate large amounts of data, implying the need for more data storage space, transmission time and computation resources. Rather than blindly selecting the highest spatial resolution, choosing appropriate flight parameters to obtain the optimal spatial resolution for crop identification classification will result in more accurate and efficient results.

Therefore in this study, blending of UAV data and Sentinel 2A are evaluated for crop type classification in the Ethiopian agriculture context.

\section{Data And Method}

This study is conducted in Oda Dhawata area which is found in Arsi zone of Oromia Region, Ethiopia. The location is found at $8^{0} 1^{\prime} 57.05^{\prime \prime} \mathrm{N}$ and $39^{0} 10^{\prime} 39^{\prime \prime} \mathrm{E}$ (figure 1). The area has wide altitudinal range from500 to 3000 masl. The area has bimodal rainfall and receiving an annual rainfall amount from $800 \mathrm{~mm}$ to $1200 \mathrm{~mm}$. Temperature in the area ranges from $10^{\circ} \mathrm{c}$ to $25^{\circ} \mathrm{c}$. Vertisol is the dominant soil 
type in the area and conducive to grow different type crops including Teff, Faba bean, barley, wheat and sorghum.

\section{UAV data}

Parrot blue grass it the drone which was employed to collected data in this study. It is multispectral sensors equipped with parrot sequoia that captures spectrally accurate high-resolution (fine grain) imagery in visible and near infrared part of electromagnetic spectrum, providing supplement to satellite and aircraft image. This small, light, multispectral camera four spectral bands in visible light and nonvisible infrared light to analyze the health status or monitoring the crop status and crop type mapping. Sequoia has $16 \mathrm{mp}$ RGB camera and internal memory of capacity of $64 \mathrm{~GB}$. The screen of these instruments indicates about orientation of the multispectral sensor and the sunshine sensor, Irradiance screen also show the light intensity of each band (Green, Red, Red Edge and near infrared). The parrot sequoia collects data of features in four spectral bands, displayed in table 1.

Table 1Available Bands and with their wavelength from the parrot sequoia

\begin{tabular}{ll}
\hline Band & Parrot sequoia (nm) \\
\hline Green & 550 \\
Red & 660 \\
Red edge & 735 \\
Near infrared & 790 \\
\hline
\end{tabular}

\section{UAV Data acquisition}

Diversified crop types like teff, Faba bean, wheat, barley and sorghum have been captured in the cluster farmland of the study area as shown in (figure 3.3)

In this study, 1862 separate images acquired, at an altitude flight of $40 \mathrm{~m}$ within four-flight mission time to cover an area of the field. Before starting the flight mission, the design of the flight path covering the area of interest was defined. The flight was done using pix4Dcapture -GRID for 2Dmaps. Captured images were orthomosaicked using pix4Dfield desktop (compatible with parrot, which is licensed for a year) and Agisoftware. Both Multispectral image and RGB image have been acquired in October 16/2020 and downloaded via server 192.168.42.2 of the drone in each flight mission in the field.

Sentinel $2 A$ acquisition

In this study Sentinel 2A data were downloaded from https://glovis.usgs.gov.com website considering the time and space alignment with the UAV data. Then sentinel 2A product was then examined for cloud free coverage and applied all the necessary preprocessing steps on the image. 
Data fusion approach

In this study the Gram Schmidt transformation method was applied for fusion of UAV and Sentinel images. The reason for choosing the Gram Schmidt approach is the criteria-based algorithm is extremely fortunate to keep the color content and offers satisfactory spatial detail enhancement compared to different algorithms. The fusion considers comparable bands of the two dataset as it shown in table $x$

Table $\mathrm{x}$ The comparison of band wavelengths $(\mathrm{nm})$ of parrot sequoia and sentinel 2A $(10 \mathrm{~m})$

\begin{tabular}{llllll}
\hline Sensor & Blue & Green & Red & Red edge & NIR \\
\hline Parrot sequoia & - & 550 & 660 & 735 & 790 \\
Sentinel 2A (10m) & 492.4 & 559.8 & 664.6 & & 864.7 \\
\hline
\end{tabular}

Training data from field

Data was collected in Oda Dhawata cluster farmland in16 October 2020. Garmin Oregon 650 GPS was used to collect training data of the cluster cropland. These points were used to train (70\%) and evaluate (30\%) data for classification.

To evaluate the both UAV and Sentinel 2A crop classification performance, a small subset of area of interest (AOI) will be tested and performed. Firstly, a broad image classification consisting of five crop type classes is performed within UAV data acquired and compared to much more area of interest (AOI) of sentinel 2A data classification of the same crop type. For both data products, the same step-by step approach will be used and tested within multispectral cameras. A more UAV focused crop classification will be performed by classifying a field consisting more than one class of crops. In another words it focuses on classical broad crop type mapping whereas the other cases really take the advantage of UAV high spatial resolution for examining the variation with sentinel $2 \mathrm{~A}$ defined classes of crop type mapping. Crop classification, orthomosaic of both multispectral and RGB, and accuracy assessment of MS have been done. First, UAV data, sentinel $2 A$ and Training location had already acquired. These all data was preprocessed (camera 35 calibration, photo alignment, dense point cloud generation - this based on the estimated camera positioning of scouting crop types. Then, it is to calculate the depth information for each camera to be combined by Ties and into single dense point cloud, which provides to generate orthomosaic. For crop classification, Random forest (RF)approach, used in machine learning algorithm on $\mathrm{R}$ software by exploring different packages of machine learning and also UAV spatial resolution impact on crop classification explored. The general workflow of UAV data and Sentinel -2A for crop classification approach is described in figure 4

\section{Results}


Image fusion

The UAV and Sentinel data fusion was conducted using the Gram-Schmidt pan sharpening technique. During fusion the high spatial resolution represents the information content of the images much more in detail and provides synthetic image close to reality when enhancing the resolution. This provides a radical improvement of the lower resolution of sentinel $2 \mathrm{~A}$ and helps for crop classification. This is very essential and useful to get accurate information of each crop types. Figure $x$ shows the sentinel $2 \mathrm{~A}$ image, UAV data and the fused one.

Crop classification

In this study two classification techniques were employed to classify crops types using the fused images. The methods are the random forest image classification techniques and the maximum likelihood classifier. For both classifications, the point data collected from field were used for training and validation. Five crop types were identified in the training data and used by the classification techniques. The identified crop types are Teff, wheat, Faba Bean, Barley and Sorghum. Accordingly the RF classification technique was applied and the crop type's maps are produced. For comparison purposes, the maximum likelihood classier was also applied on the fused image (figure).

Accuracy Assessments

Accuracy assessment was done to validate the classified map of crop types based on fuse image in both classification techniques. In the assessment overall accuracy, user's accuracy and producer accuracy were used to measure the performance. Accordingly, the overall accuracy for RF algorithm is $94 \%$ and the maximum likelihood classifier is $90 \%$. This implies the classification techniques and the data used for classification is quite important to obtain a better classified map. The statistical accuracy assessments of both classifications were shown in (Table 8 and 9).

Table 8. Accuracy Assessment table result using Random forest approach classifier for fusion and UAV 


\begin{tabular}{|l|l|l|l|l|l|l|}
\hline Crop types & Teff & Wheat & Faba bean & Barley & Sorgum & Total user \\
\hline Teff & 6 & 0 & 0 & 0 & 0 & 6 \\
\hline Wheat & 0 & 5 & 1 & 0 & 0 & 6 \\
\hline Faba bean & 0 & 0 & 8 & 0 & 0 & 8 \\
\hline Barley & 0 & 0 & 0 & 5 & 0 & 5 \\
\hline sorghum & 0 & 0 & 1 & 0 & 4 & 5 \\
\hline $\begin{array}{l}\text { Total } \\
\text { producer }\end{array}$ & 6 & 5 & 10 & 5 & 4 & 30 \\
\hline
\end{tabular}

Over all Accuracy maximum likelihood $=\mathbf{2} 8 / \mathbf{3 0} * \mathbf{1 0 0}=\mathbf{9} 4 \%$

Table Accuracy Assessment table result using Maximum Likelihood classification

\begin{tabular}{|l|l|l|l|l|l|l|}
\hline Crop type & Teff & Wheat & Faba bean & Barley & Sorgum & Total user \\
\hline Teff & 6 & 0 & 0 & 0 & 0 & 6 \\
\hline Wheat & 0 & 5 & 1 & 0 & 0 & 6 \\
\hline Faba bean & 0 & 0 & 8 & 0 & 0 & 8 \\
\hline Barley & 0 & 0 & 0 & 5 & 0 & 5 \\
\hline sorghum & 0 & 0 & 2 & 0 & 3 & 5 \\
\hline $\begin{array}{l}\text { Total } \\
\text { producer }\end{array}$ & 6 & 5 & 11 & 5 & 3 & 30 \\
\hline
\end{tabular}

Over all Accuracy maximum likelihood $=\mathbf{2 7} / \mathbf{3 0} * \mathbf{1 0 0}=\mathbf{9 0} \%$

In general, the Random forest algorithm produced very good results and the accuracy assessment was very good. Firstly, the main emphasize of this project was to know the potential of Blending of UAV ad Sentinel 2A for crop type mapping. The fused image, the pixel size of UAV improves the sentinel 2A (the low resolution) data. Classifying at high spatial resolution produces the very highest accuracy for crop type mapping and both sensors (UAV and S2A). Most of the literature states that very similar results can be obtained from both classification approaches when a noncomplex scene is being used, however if the scene is complex then RFs are superior. Maximum likelihood has been around for a long time and has been research extensively. It can offer satisfactory results and is easy to perform. Random forests are newer in comparison and offer a power full approach for remote sensing classification approach. Random forest classification uses a large number of decision trees to get the result. Each tree is created using random sample selection. A random subset of input predictors is used at every tree to split it making new node. The results gathered from the majority vote created by all the trees in the process. 
Overall, it was concluded that the fusion of UAV and S2A approach performs better than separate sensors in discriminating crop type classes and co-existing crop type classes in heterogeneous landscapes because of its high spectral and spatial resolution (Taona, 2019)

\section{Conclusion}

In this study Sentinel 2A and UAV has been fused together using Gram Schmidt (GS) technique for crop type mapping using Random forest algorithm and Maximum likelihood classification method. The accuracy assessment evaluated for each classification approach to determine the best method, bands, and sensor to use when classifying crop type in heterogeneous landscape of the cluster farmland. From the fused approach, the Random forest classification algorithm obtained high classification accuracy $94 \%$, the maximum likelihood classification accuracy was $90 \%$ and from UAV data $84 \%$ using Random forest. This is showing that Random forest classification in fusion approach have high capability of the moderate spatial and spectral resolution of the data in accurately identifying and distinguishing the diversified crop type mapping. Regarding the performance of the classifier, it was observed that RF algorithm produced high classification accuracy and it was for field-based crop classification using multispectral data. The study emphasized that RF is effective and accurate means for agricultural crop identification and mapping. Generally, it is found that both classifications were good enough to categorize crop types with fair accuracy level. Comparing the performance of the two methods the Random forest approach classified at higher accuracy level than the maximum likelihood classier. This implies that the potential of using fused image with better classification technique to classify crop field in the Ethiopian agricultural context.

\section{References}

Ahmed, O.S., Shemrock, A., Chabot, D., Dillon, C., Williams, G., Wasson, R. and Franklin, S.E., 2017. Hierarchical land cover and vegetation classification using multispectral data acquired from an unmanned aerial vehicle. International journal of remote sensing, 38(8-10), pp.2037-2052.

Asgarian, A.Soffianian, A. and Pourmanafi, S., 2016. Crop type mapping in a highly fragmented and heterogeneous agricultural landscape: A case of central Iran using multi-temporal Landsat 8 imagery. Computers and Electronics in Agriculture, 127, pp.531-540.

Atkinson, P.M., 1997. Selecting the spatial resolution of airborne MSS imagery for small-scale agricultural mapping. International Journal of Remote Sensing, 18(9), pp.1903-1917.

Ballesteros, R., Ortega, J.F., Hernández, D. and Moreno, M.A., 2014. Applications of georeferenced highresolution images obtained with unmanned aerial vehicles. Part I: Description of image acquisition and processing. Precision Agriculture, 15(6), pp.579592.

Bansod, Babankumar, Rangoli Singh, Ritula Thakur, and Gaurav Singhal. "A comparision between satellite based and drone based remote sensing technology to achieve sustainable development: A review." 
Journal of Agriculture and Environment for International Development (JAEID) 111, no. 2 (2017): 383407.

Chen, Z., Wang, L. and Liu, J., 2017. Selecting appropriate spatial scale for mapping plasticmulched farmland with satellite remote sensing imagery. Remote Sensing, 9(3), p.265.

Chilalo Agricultural Development Unit (CADU) “General Agricultural Survey, 1972. Planning and Evaluation Section." CADU Publications No. 82. (1973).

Chilot Yirga, Hailu Beyene, L. Zewdie, and D.G. Tanner "Initial Results of Informal survey: Kulumsa Mixed Farming Zone." Institute of Agricultural Research (EIAR)Addis Ababa, Ethiopia Working Paper No.10. (1989).

Chuvieco, E. (2016). Fundamentals of Satellite Remote Sensing. An Environmental Approach. (2nd ed.). Boca Raton, FL: CRC Press.

Colomina, I. and Molina, P., 2014. Unmanned aerial systems for photogrammetry and remote sensing: A review. ISPRS Journal of photogrammetry and remote sensing, 92, pp.79-97.

Colwell, R. "Determining the prevalence of certain cereal crop diseases by means of aerial photography." Hilgardia 26, no. 5 (1956): 223-286. 65

Conrad, Christopher, Sebastian Fritsch, Julian Zeidler, Gerd Rücker, and Stefan Dech. "Per-field irrigated crop classification in arid Central Asia using SPOT and ASTER data." Remote Sensing 2, no. 4 (2010): 1035-1056.

Del Pozo, Susana, Pablo Rodríguez-Gonzálvez, David Hernández-López, and Beatriz FelipeGarcía. "Vicarious radiometric calibration of a multispectral camera on board an unmanned aerial system." Remote Sensing 6, no. 3 (2014): 1918-1937.

Deloitte, 2019. Insurance Industry Drone Use Is Flying Higher and Farther.

httpsm://www2.deloitte.com/us/en/pages/financial-services/articles/infocus-drone-usebyinsuranceindustry-flying-higher-farther.html. (Accessed 13 March 2019).

Diaz-Varela, R.A., Zarco-Tejada, P.J., Angileri, V. and Loudjani, P., 2014. Automatic identification of agricultural terraces through object-oriented analysis of very highresolution DSMs and multispectral imagery obtained from an unmanned aerial vehicle.

Journal of environmental management, 134, pp.117-126.

Drusch, M., Del Bello, U., Carlier, S., Colin, O., Fernandez, V., Gascon, F., Hoersch, B., Isola, C., Laberinti, P., Martimort, P. and Meygret, A., 2012. Sentinel-2: ESA's optical highresolution mission for GMES operational services. Remote sensing of Environment, 120, pp.25-36. 
El Hajj, M., Bégué, A., Guillaume, S. and Martiné, J.F., 2009. Integrating SPOT-5 time series, crop growth modeling and expert knowledge for monitoring agricultural practices-The case of sugarcane harvest on Reunion Island. Remote Sensing of Environment, 113(10), pp.2052-2061.

Elarab, M., Ticlavilca, A.M., Torres-Rua, A.F., Maslova, I. and McKee, M., 2015. Estimating chlorophyll with thermal and broadband multispectral high-resolution imagery from an unmanned aerial system using relevance vector machines for precision agriculture. International Journal of Applied Earth Observation and Geoinformation, 43, pp.32-42.

Freeman, P.K. and Freeland, R.S., 2015. Agricultural UAVs in the US: potential, policy, and hype. Remote Sensing Applications: Society and Environment, 2, pp.35-43.

Gao, Feng, Thomas Hilker, Xiaolin Zhu, Martha Anderson, Jeffrey Masek, Peijuan Wang, and

Yun Yang. "Fusing Landsat and MODIS data for vegetation monitoring." IEEE Geoscience and Remote Sensing Magazine 3, no. 3 (2015): 47-60. 66

Ge, Y., Thomasson, J.A. and Sui, R., 2011. Remote sensing of soil properties in precision agriculture: A review. Frontiers of Earth Science, 5(3), pp.229-238.

Immitzer, M., Vuolo, F. and Atzberger, C., 2016. First experience with Sentinel-2 data for crop and tree species classifications in central Europe. Remote sensing, 8(3), p.166.

Jenerowicz, A.;Woroszkiewicz,M. The pan- sharpening of satellite and UAV imagery for agricultural applications. In Remote Sensing for Agriculture, Ecosystems, and

Hydrology Xviii; Neale, C.M.U.,Maltese, A., Eds.; Spie-Int Soc Optical Engineering: Bellingham, DC, USA, 2016; Volume 9998.

Kwarteng, P., and A. Chavez. "Extracting spectral contrast in Landsat Thematic Mapper image data using selective principal component analysis." Photogramm. Eng. Remote Sens 55, no. 1 (1989): 339-348.

Laben, Craig A., and Bernard V. Brower. "Process for enhancing the spatial resolution of multispectral imagery using pan-sharpening." U.S. Patent 6,011,875, issued January 4, 2000.

Lelong, Camille CD, Philippe Burger, Guillaume Jubelin, Bruno Roux, Sylvain Labbé, and Frédéric Baret. "Assessment of unmanned aerial vehicles imagery for quantitative monitoring of wheat crop in small plots." Sensors 8, no. 5 (2008): 3557-3585.

Letey, J.O.H.N., 1958. Relationship between soil physical properties and crop production. In Advances in soil science (pp. 277-294). Springer, New York, NY.

Lexander, A. "The Changing Rural Society in Arsi Land: Some Findings from Field Study 1966- 
67." CADU Publication No. 13 (1968).

Li, L., Friedl, M.A., Xin, Q., Gray, J., Pan, Y. and Frolking, S., 2014. Mapping crop cycles in China using MODIS-EVI time series. Remote Sensing, 6(3), pp.2473-2493.

Malenovský, Z., Rott, H., Cihlar, J., Schaepman, M. E., García-Santos, G., Fernandes, R. \& Berger, M. 2012. Sentinels for science: Potential of Sentinel-1, -2, and-3 missions for scientific observations of ocean, cryosphere, and land. Remote Sensing of Environment, 120, 91-101.

Mesas-Carrascosa, F.J., Rumbao, I.C., Berrocal, J.A.B. and Porras, A.G.F., 2014. Positional quality assessment of orthophotos obtained from sensors onboard multi-rotor UAV platforms. Sensors, 14(12), pp.22394-22407.

Michez, A., Piégay, H., Lisein, J., Claessens, H. and Lejeune, P., 2016. Classification of riparian forest species and health condition using multi-temporal and hyperspatial imagery from unmanned aerial system. Environmental monitoring and assessment, 188(3), p.146.

Morellato, L.P.C. and Silveira, F.A., 2018. Plant life in campo rupestre: new lessons from an ancient biodiversity hotspot. Flora, 238, pp.1-10. 67

Newcome, Laurence R. Unmanned aviation: a brief history of unmanned aerial vehicles.

American Institute of Aeronautics and Astronautics, 2004.

Ouzemou, J.E., El Harti, A., Lhissou, R., El Moujahid, A., Bouch, N., El Ouazzani, R.,

Bachaoui, E.M. and El Ghmari, A., 2018. Crop type mapping from pansharpened Landsat 8 NDVI data: A case of a highly fragmented and intensive agricultural system.

Remote Sensing Applications: Society and Environment, 11, pp.94-103.

Pajares, G., 2015. Overview and current status of remote sensing applications based on unmanned aerial vehicles (UAVs). Photogrammetric Engineering \& Remote Sensing, 81(4), pp.281-330.

Pohl, Cle, and John L. Van Genderen. "Review article multisensor image fusion in remote sensing: concepts, methods and applications." International journal of remote sensing 19, no. 5 (1998): 823854.

Sarp, Gulcan. "Spectral and spatial quality analysis of pan-sharpening algorithms: A case study in Istanbul." European Journal of Remote Sensing 47, no. 1 (2014): 19-28.

Schmedtmann, J. and Campagnolo, M.L., 2015. Reliable crop identification with satellite imagery in the context of common agriculture policy subsidy control. Remote Sensing, 7(7), pp.9325-9346. 
Shahbazi, M., Théau, J. and Ménard, P., 2014. Recent applications of unmanned aerial imagery in natural resource management. GIScience \& Remote Sensing, 51(4), pp.339-365. Srivastava, Kshitij, Aman Jain Bhutoria, Jyoti K. Sharma, Aakash Sinha, and Prem Chandra Pandey. "UAVs technology for the development of GUI based application for precision agriculture and environmental research." Remote Sensing Applications: Society and Environment 16 (2019): 100258.

Stöcker, C., Bennett, R., Nex, F., Gerke, M. and Zevenbergen, J., 2017. Review of the current state of UAV regulations. Remote sensing, 9(5), p.459.

Stroppiana, D., Migliazzi, M., Chiarabini, V., Crema, A., Musanti, M., Franchino, C. and Villa, P., 2015, July. Rice yield estimation using multispectral data from UAV: A preliminary experiment in northern Italy. In 2015 IEEE International Geoscience and Remote Sensing Symposium (IGARSS) (pp. 4664-4667). IEEE.

Taona, Mazarire Theresa. "Crop type mapping in a highly heterogeneous agriculture landscape: a case of Marble hall using multi-temporal landsat 8 and sentinel 2 imageries." PhD diss., 2019. 68

Tsouros, D.C., Bibi, S. and Sarigiannidis, P.G., 2019. A review on UAV-based applications for precision agriculture. Information, 10(11), p.349.

Veloso, A., Mermoz, S., Bouvet, A., Le Toan, T., Planells, M., Dejoux, J.F. and Ceschia, E., 2017. Understanding the temporal behavior of crops using Sentinel-1 and Sentinel-2-like data for agricultural applications. Remote sensing of environment, 199, pp.415-426.

Vuolo, F., Neuwirth, M., Immitzer, M., Atzberger, C. and Ng, W.T., 2018. How much does multi-temporal Sentinel-2 data improve crop type classification. International journal of applied earth observation and geoinformation, 72, pp.122-130.

Vyas, S.P., Oza, M.P. and Dadhwal, V.K., 2005. Multi-crop separability study of Rabi crops using multitemporal satellite data. Journal of the Indian Society of Remote Sensing, 33(1), pp.75-79.

Warren, G. and Metternicht, G., 2005. Agricultural applications of high-resolution digital multispectral imagery. Photogrammetric Engineering \& Remote Sensing, 71(5), pp.595602.

Whitehead, K. and Hugenholtz, C.H., 2014. Remote sensing of the environment with small unmanned aircraft systems (UASs), part 1: A review of progress and challenges. Journal of Unmanned Vehicle Systems, 2(3), pp.69-85.

Yadav, R.L., 1998. Factor productivity trends in a rice-wheat cropping system under long-term use of chemical fertilizers. Experimental Agriculture, 34(1), pp.1-18.

Yilmaz, Volkan, and Oguz Gungor. "Fusion of very high-resolution UAV images with criteriabased image fusion algorithm." Arabian Journal of Geosciences 9, no. 1 (2016): 59. 
Zena, Tiruneh. "Economic Characteristics of Peasant Families in the Asasa Area." Chilalo Awraja (Assela ARDU Publication, No. 3) (1976).

Zhang, J., Cheng, Y., Zhang, F., Yue, D., Guo, X., Dong, H., Wang, J. and Tang, H., 2012.

Crop's planting information extraction based on multi-temporal remote sensing images. Transactions of the Chinese Society of Agricultural Engineering, 28(2), pp.134-141.

Zhao, L., Shi, Y., Liu, B., Hovis, C., Duan, Y. and Shi, Z., 2019. Finer Classification of Crops by Fusing UAV Images and Sentinel-2A Data. Remote Sensing, 11(24), p.3012.

\section{Figures}

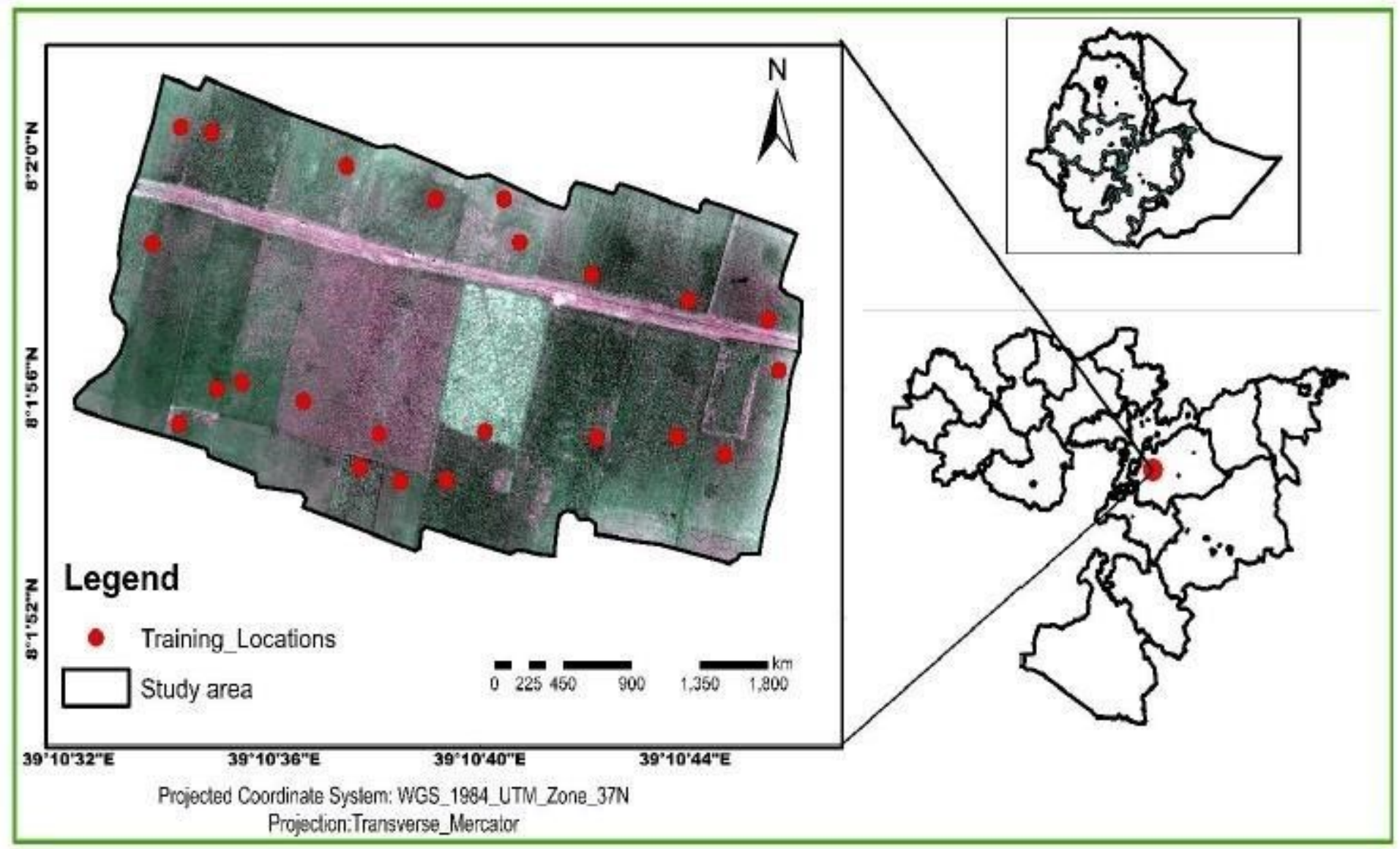

Figure 1

study area 

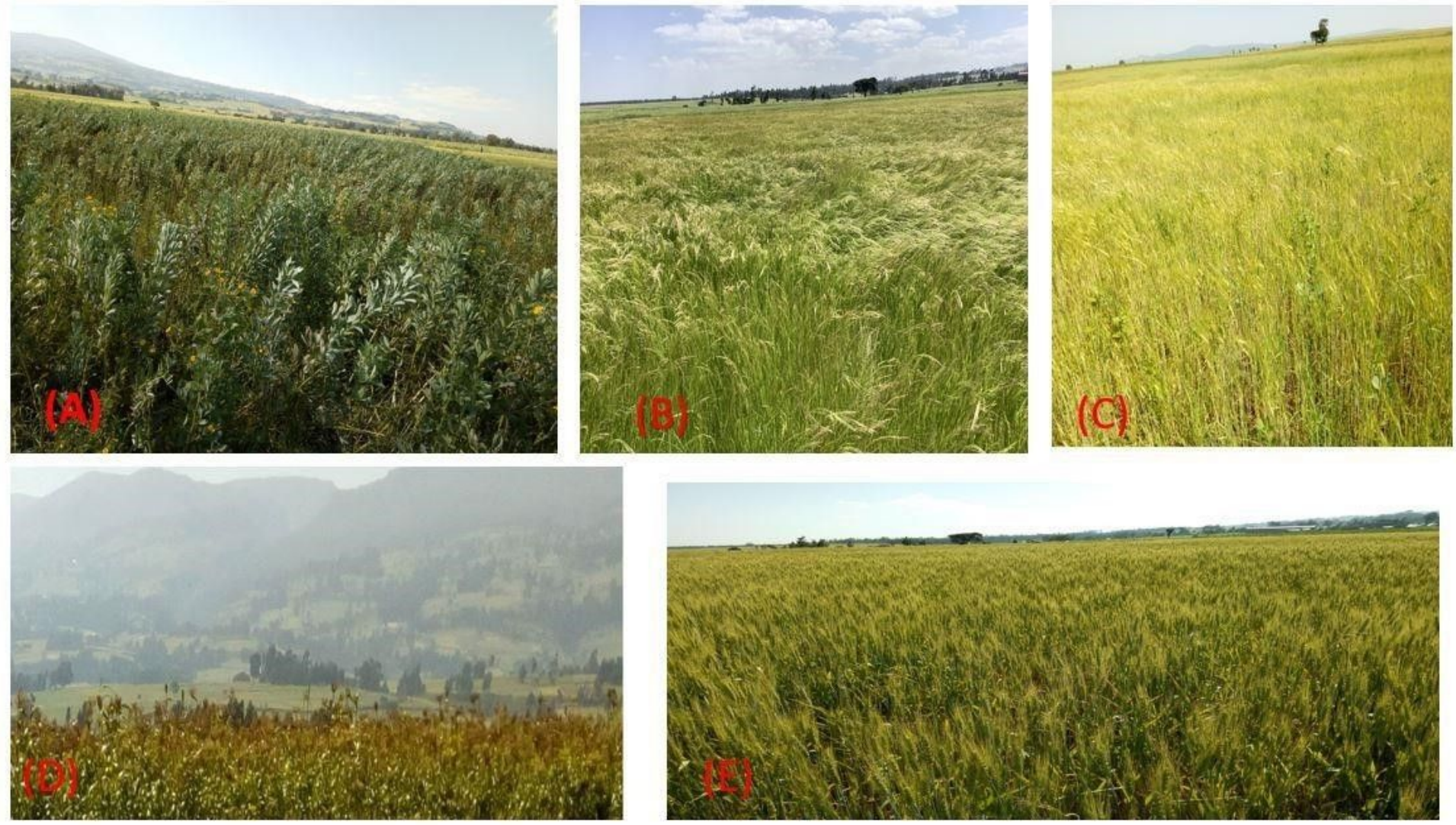

Figure 2

Crop types in cluster farmlands :(A)-Faba bean, (B)-Teff, (C)-Barley, (D)-Sorghum and (E) wheat 


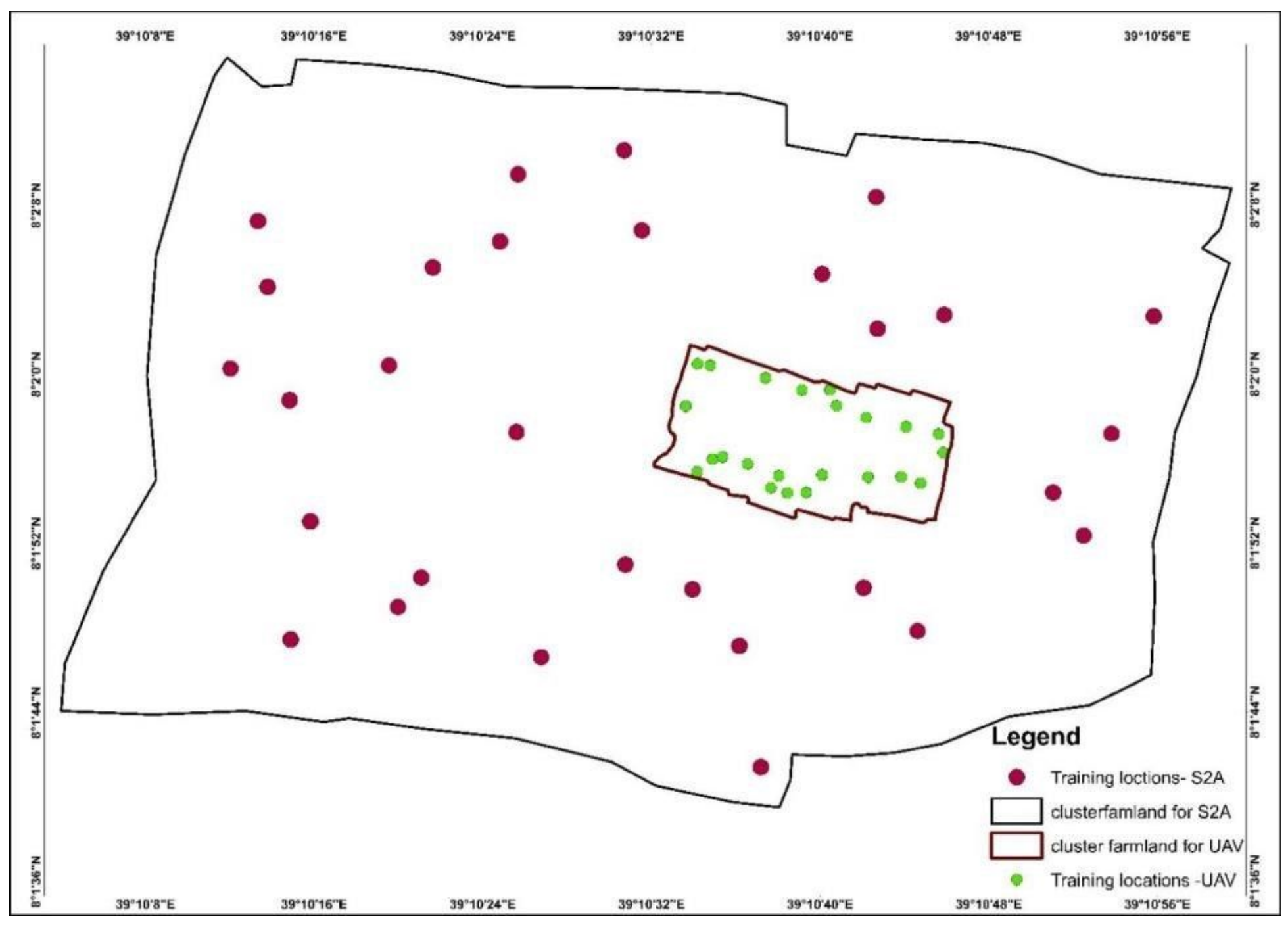

Figure 3

Point sampled field data collected the study area 


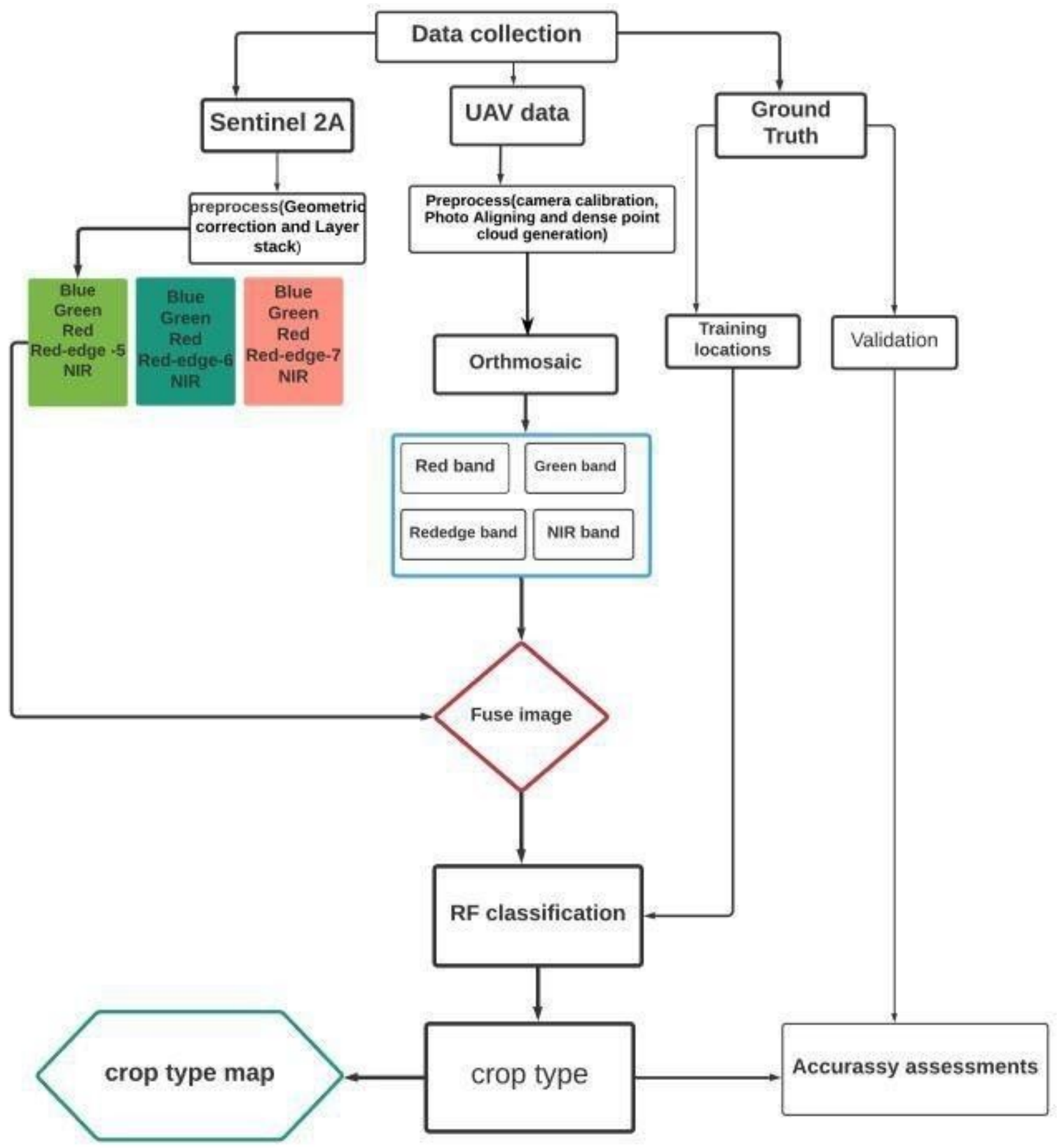

Figure 4

general work flow chart of the Research 


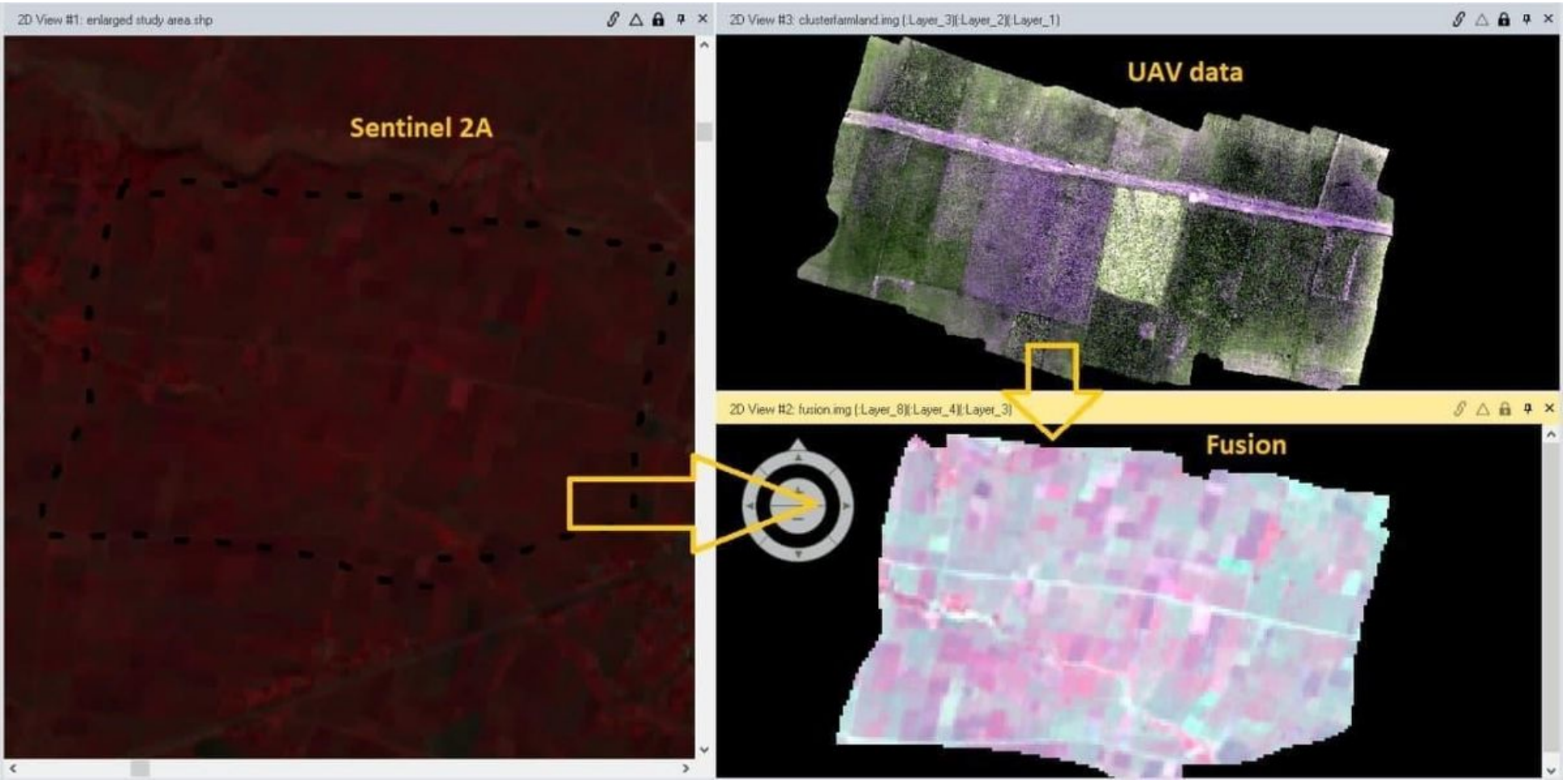

\section{Figure 5}

Fusion of UAV and Sentinel 2A
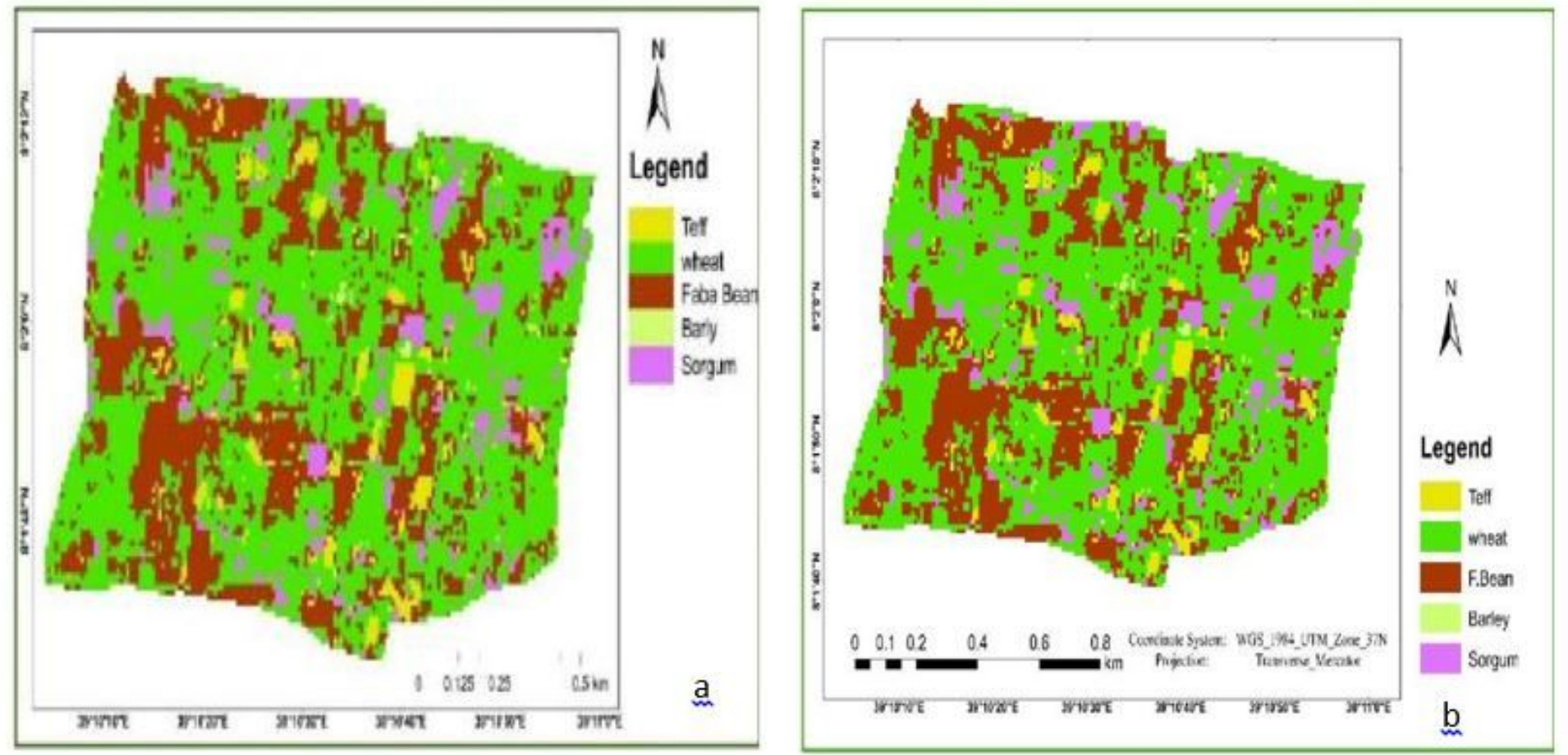

Figure 6

Crop type classification map using Random forest (a) and maximum likelihood classifiers (b) 